\title{
High-flow Nasal Cannula is Superior to Standard Face-Mask Oxygen Therapy in Viral Bronchiolitis
}

\author{
Esra Türe ${ }^{1, \star}$, Abdullah Yazar ${ }^{1}$, Fatih Akın ${ }^{1}$, Sevgi Pekcan ${ }^{2}$
}

${ }^{1}$ Department of Pediatric Emergency, Meram Medical Faculty, Necmettin Erbakan University, Konya, Turkey ${ }^{2}$ Department of Pediatric Pulmonology, Meram Medical Faculty, Necmettin Erbakan University, Konya, Turkey

*Correspondence

dresrature@hotmail.com (Esra Türe)

\begin{abstract}
Objectives: High-flow nasal cannula (HFNC) has arisen as a novel treatment method for providing high-flow oxygen support. It can be used for patients of all age groups, provides respiratory support in respiratory tract diseases, and its use is rapidly increasing. The aim of the study was to compare the effectiveness of oxygen therapies with HFNC and a non-rebreathing face mask (NFM) with a reservoir bag through changes in vital signs before and after treatment. Methods: Patients aged under two years who were diagnosed as having acute bronchiolitis were included in study. Of the randomly selected patients, one-half was given HFNC oxygen therapy and the other half was given standard oxygen support via an NFM. Results: There was a significant reduction in respiration rates (RR) at the 3rd hour and in heart rate (HR) at the 6th hour of treatment compared with NFM. Time to normalization of HR and RR according to age and length of hospital stay were shorter and need for intensive care support was less in those receiving HFNC oxygen support. Conclusions: HFNC significantly shortens length of hospital stay and duration of oxygen therapy compared with standard oxygen. The authors believe that the effectiveness of treatment or response to treatment could be evaluated using HR and RR monitoring. A flow rate up to 25 $\mathrm{L} / \mathrm{min}$ could be used for patients aged under two years.
\end{abstract}

\section{Keywords}

Bronchiolitis, High-Flow Nasal Cannula Oxygen Therapy, Child

\section{Introduction}

Lower respiratory tract infections are some of the most commonly encountered causes of admission to emergency departments of hospitals and hospitalizations in the pediatric population, and are among the leading causes of morbidity and mortality in children worldwide [1]. Acute bronchiolitis $(\mathrm{AB})$ is characterized by wheezing, cough, tachypnea, retractions in the thoracic wall, and prolonged expiration. It is caused frequently by viral agents and progresses with inflammation of the bronchioles in children aged under two years [2]. The diagnosis of $A B$ is based on patient's history and physical examination; routine radiographic or laboratory studies are not necessary [3]. Although there are many studies on the use of steroids, bronchodilators, nebulized hypertonic saline, and epinephrine [4], supportive care, monitoring, and oxygen support forms the fundamentals of the treatment [5].
In patients with $\mathrm{AB}$, recent studies have demonstrated that the need for invasive mechanical ventilation (IMV) is prevented and intensive care requiremet is reduced with early respiratory support provided using non-invasive ventilation (NIV) and high-flow nasal cannula (HFNC) oxygen therapy $[6,7]$. HFNC has arisen as a novel treatment method for providing high-flow oxygen support, it can be used for patients of all age groups, provides respiratory support in respiratory tract diseases, and its use is rapidly increasing $[8,9]$. Air is blended with oxygen, humidified, and warmed, and delivered with positive airway pressure. In addition to effects such as promoting mucociliary clearance and enabling easier removal of secretions, HFNC provides more effective oxygenation and gas exchange through rinsing of the nasopharyngeal dead space via its high-flow effect. Thus, it is thought that it helps in the resolution of atelectasis, improves ventilation, and reduces the need for NIV and IMV by reducing inspiratory resistance and mucus 
TA B L E 1. Clinical and epidemiologic characteristics of the patients.

\begin{tabular}{|c|c|c|c|c|}
\hline & All Patients $(n=75)$ & $\begin{array}{l}\text { Oxygen via Mask with } \\
\text { Reservoir }(n=38)\end{array}$ & $\begin{array}{l}\text { Oxygen via High-flow } \\
\text { Nasal Cannula }(n=37)\end{array}$ & $\mathbf{p}$ \\
\hline Age (Month) & $10.33 \pm 6.32$ & $10.15 \pm 5.8$ & $10.51 \pm 6.90$ & NS \\
\hline Median (month) & 9 & 9.5 & 8 & \\
\hline Minimum-maximum (month) & $2-24$ & $2-24$ & $3-24$ & \\
\hline Female (n, \%) & $35(46.7 \%)$ & $18(47.4 \%)$ & $17(45.9 \%)$ & NS \\
\hline Male (n, \%) & $40(53.3 \%)$ & $20(52.6 \%)$ & $20(54.1 \%)$ & NS \\
\hline Moderate Attack Score (n, \%) & $39(52 \%)$ & $20(52.6 \%)$ & $19(51.4 \%)$ & NS \\
\hline Severe Attack Score (n, \%) & $36(48 \%)$ & $18(47.4 \%)$ & $18(48.6 \%)$ & NS \\
\hline Mean Attack Score & $8.36 \pm 1.94$ & $8.15 \pm 1.80$ & $8.56 \pm 2.08$ & NS \\
\hline
\end{tabular}

NS = not significant

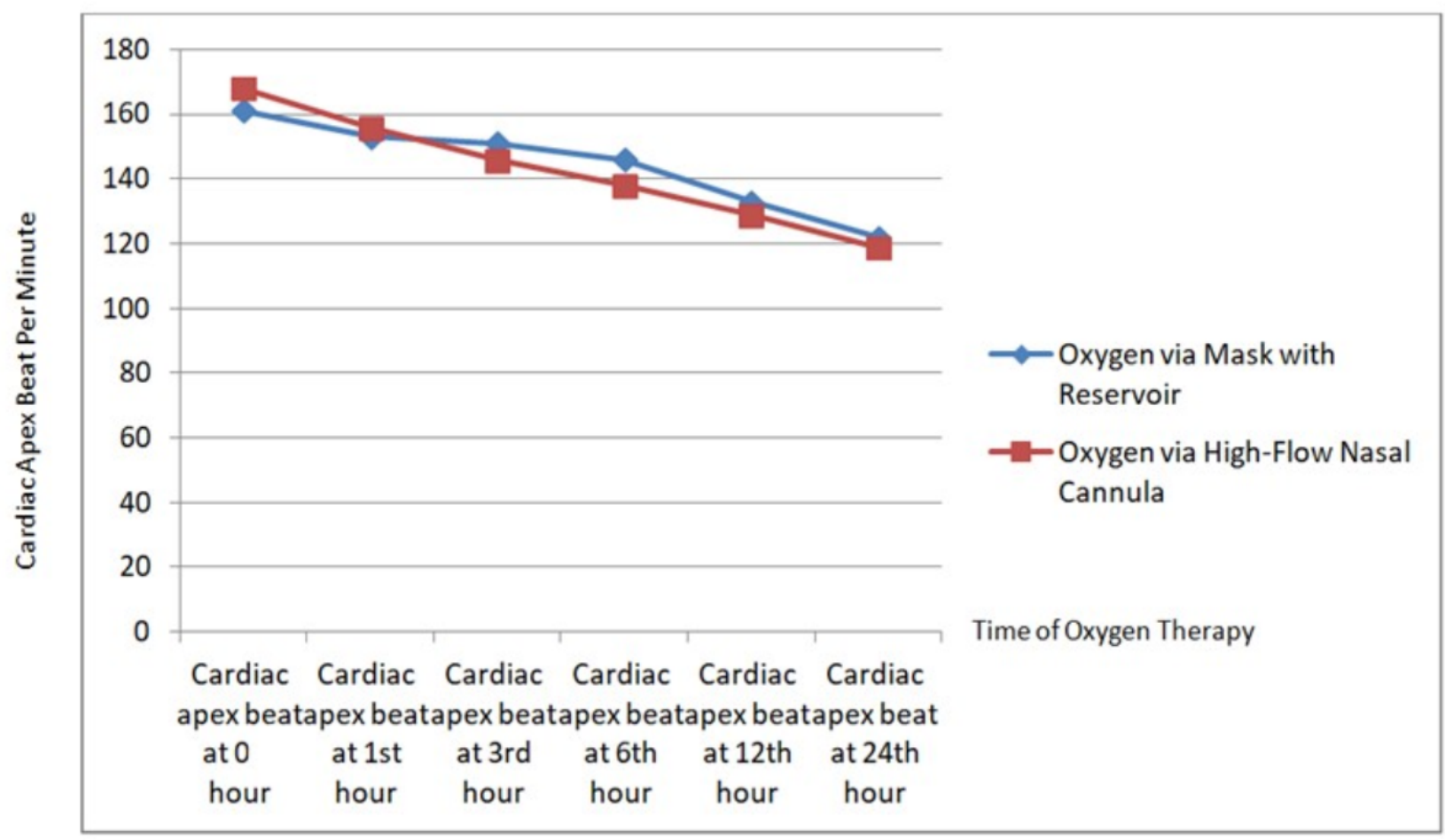

F I G U R E 1. Cardiac apex beat per minute values within the first 24 hours via high-flow nasal cannula and standard oxygen therapy.

formation $[10,11]$.

The aim this study was to compare the effectiveness of oxygen therapies with HFNC and non-rebreathing face masks (NFM) with a reservoir bag through changes in vital signs before and after treatment, duration of oxygen support, oxygen need, length of hospital stay, treatment success for 24 hours, and whether there was a need for intensive care treatment.

\section{Subjects and Methods}

Patients aged under two years who were admitted to Necmettin Erbakan University Faculty of Medicine Hospital Pediatric Emergency Department and were diagnosed as having $\mathrm{AB}(\mathrm{N}=382)$ between November
2017 and March 2018 were included in the study. The study was approved by ethics committee (2018/1263) and informed consent was obtained from each participant. After dividing the patients into groups as mild, moderate or severe $\mathrm{AB}$ using the adjusted scoring system of Wang et al. [12], patients with moderate and severe $\mathrm{AB}$ were included in the study. Of the patients with AB, 265 (69.4\%) were excluded from the study because they had a mild bronchiolitis score. Also, 42 (11\%) were excluded because they had a disease such as bronchopulmonary dysplasia, cystic fibrosis, prematurity, supportive ventilation during neonatal period, congenital heart disease or immunodeficiency or because they received bronchodilator or corticosteroid treatment within 


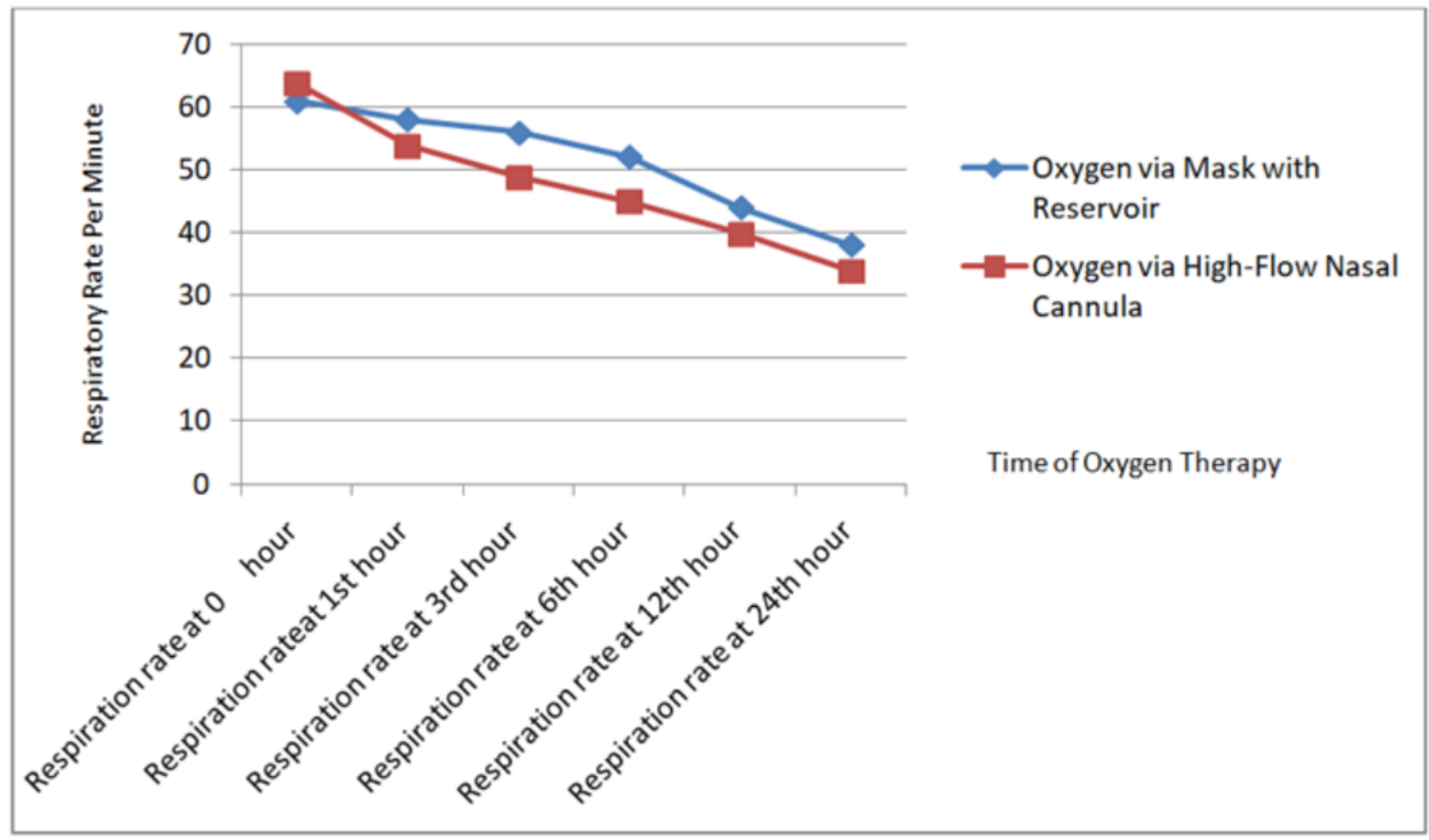

F I G U R E 2. Respiration rate values within the first 24 hours via high-flow nasal cannula and standard oxygen therapy.

the last two weeks. The treatment method was randomly selected for the patients, one-half was given HFNC and the other half was given standard oxygen support via NFM. All patients were given inhaler salbutamol treatment three times with 20-minute intervals. For those who did not benefit from the salbutamol treatment, nebulized epinephrine with 4-hour intervals was added to their treatments, and if they did not benefit again, systemic steroid treatment was added. The NFM group received oxygen therapy at a rate of $10-15 \mathrm{~L} / \mathrm{min}$ administered via an NFM with reservoir. The flow rate via HFNC was adjusted as $2 \mathrm{~L} / \mathrm{kg} / \mathrm{min}$ for patients weighing $<10 \mathrm{~kg}$ and $1 \mathrm{~L} / \mathrm{kg} / \mathrm{min}$ for those weighing $>10 \mathrm{~kg}$ and, when necessary, it was gradually increased, but not exceeding $25 \mathrm{~L} / \mathrm{min}$. The fraction of inspired oxygen concentration $\left(\mathrm{FiO}_{2}\right)$ at the beginning was adjusted to $40 \%$, and gradually increased when necessary. Oxygen saturation $\left(\mathrm{SpO}_{2}\right)$ was tried to be kept between 94 to $98 \%$. When the HFNC flow rate remained stable at $2 \mathrm{~L} / \mathrm{min}$, standard oxygen therapy was continued. The device temperature was adjusted as $33-34^{\circ} \mathrm{C}$ and reduced and decreased in accordance with the comfort of the patients. HFNC oxygen support was administered by using a Fisher and Paykel Healthcare myAIRVO 2 system. Of the patients for whom treatment was initiated, cardiac apex beat (HR), respiration rate (RR), and $\mathrm{SpO}_{2}$ at 0 hours, $1^{\text {st }}$ hour, $3^{\text {rd }}$ hour, $6^{\text {th }}$ hour, $12^{\text {th }}$ hour, and $24^{\text {th }}$ hour, as well as duration of oxygen support, whether there was an increase in oxygen need, time to a reduction in HR and RR by $20 \%$, time to normalization of HR and RR, length of hospital stay, success of treatment within 24 hours, intensive care requirement, and characteristics such as age and sex were recorded. Adverse effects due to the use of HFNC such as nasal mucosal trauma and/or bleeding, vomiting, and pneumothorax were recorded. Failure of vital signs to restore to age-adjusted normal range and of $\mathrm{SpO}_{2}$ to return back to normal within 24 hours were considered as treatment failure.

\subsection{Statistical analysis}

Statistical analysis of the study was performed by using the Statistical Package for the Social Sciences for Windows ver. 20.0 package program. Continuous variables are expressed as mean \pm standard deviation. Descriptive and frequency analyses were used for the distribution of the data, and Chi-square tests were used for the comparison of two independent groups in frequency data. The independent ttest was used for the comparison of the means of two independent groups. In the correlation analysis of continuous variables, Pearson's correlation analysis was performed for those exhibiting normal distribution and Spearman correlation analysis was used for variables that did not exhibit normal distribution. For all statistical analyses, the level of statistical significance was considered as $<0.05$.

\section{Results}

Patients with moderate and severe attack scores $(\mathrm{n}=75$, $19.6 \%$ ) were included in the study. The epidemiologic 
TA B L E 2. Mean cardiac apex beat, respiration rate and oxygen saturation per minute within first 24 hours.

\begin{tabular}{|c|c|c|c|}
\hline & $\begin{array}{l}\text { Oxygen via Mask with } \\
\text { Reservoir }(n=38)\end{array}$ & $\begin{array}{l}\text { Oxygen via High-flow } \\
\text { Nasal Cannula }(n=37)\end{array}$ & $\mathbf{p}$ \\
\hline Cardiac apex beat at 0 hours & $161.02 \pm 15.42$ & $168.75 \pm 15.75$ & 0.035 \\
\hline Respiration rate at 0 hours & $61.97 \pm 8.62$ & $64.18 \pm 10.83$ & NS \\
\hline Oxygen saturation at 0 hours & $90.47 \pm 2.31$ & $88.81 \pm 2.63$ & NS \\
\hline Cardiac apex beat at 1 st hour & $153.28 \pm 20.46$ & $156.67 \pm 15.50$ & NS \\
\hline Respiration rate at 1 st hour & $58.31 \pm 9.96$ & $54.86 \pm 9.73$ & NS \\
\hline Oxygen saturation at 1 st hour & $94.23 \pm 2.35$ & $94.62 \pm 1.75$ & NS \\
\hline Cardiac apex beat at 3 rd hour & $151.42 \pm 17.03$ & $146.45 \pm 17.44$ & NS \\
\hline Respiration rate at $3 \mathrm{rd}$ hour & $56.47 \pm 10.99$ & $49.27 \pm 10.40$ & 0.005 \\
\hline Oxygen saturation at 3rd hour & $95.78 \pm 2.99$ & $95.94 \pm 1.68$ & NS \\
\hline Cardiac apex beat at 6 th hour & $146.39 \pm 15.82$ & $138.75 \pm 16.40$ & 0.044 \\
\hline Respiration rate at 6 th hour & $52.68 \pm 9.07$ & $45.24 \pm 11.50$ & 0.003 \\
\hline Oxygen saturation at 6 th hour & $97.23 \pm 1.14$ & $97.02 \pm 1.78$ & NS \\
\hline Cardiac apex beat at 12 th hour & $133.68 \pm 13.79$ & $129.59 \pm 16.35$ & NS \\
\hline Respiration rate at 12 th hour & $44.84 \pm 7.40$ & $40.91 \pm 9.93$ & NS \\
\hline Oxygen saturation at 12 th hour & $98.47 \pm 1.67$ & $98.45 \pm 1.72$ & NS \\
\hline Cardiac apex beat at 24 th hour & $122.57 \pm 10.71$ & $119.83 \pm 14.66$ & NS \\
\hline Respiration rate at 24 th hour & $38.55 \pm 7.52$ & $34.56 \pm 7.08$ & 0.021 \\
\hline Oxygen saturation at 24th hour & $99.36 \pm 1.30$ & $99.64 \pm 0.75$ & NS \\
\hline
\end{tabular}

NS = not significant

and clinical characteristics of the patients are provided in Table 1. During their treatments, $25(65.8 \%)$ patients who received NFM oxygen support and $14(37.8 \%)$ patients who received HFNC oxygen therapy developed a need for increased oxygen support. In $4(10.8 \%)$ of 38 patients receiving NFM oxygen therapy, HFNC oxygen therapy was initiated because of increased oxygen need and insufficient recovery in clinical presentation. It was determined that $25(64.1 \%)$ of 39 patients who needed increased oxygen support were in the NFM oxygen support group, which was statistically significant $(\mathrm{p}=0.021)$.

During the follow-ups of the patients, the mean HR, $\mathrm{RR}$, and $\mathrm{SpO}_{2}$ were compared between the groups. The mean RR at the $3^{r d}$ hour $(\mathrm{p}=0.005)$, HR at the $6^{\text {th }}$ hour $(\mathrm{p}=0.044), \mathrm{RR}$ at $6^{\text {th }}$ hour $(\mathrm{p}=0.003)$, and the mean $\mathrm{RR}$ at the $24^{\text {th }}$ hour $(\mathrm{p}=0.021)$ were determined to be statistically significantly lower in those receiving HFNC oxygen support. No statistical significance was determined between the means of the other parameters at the $1^{\text {st }}, 3^{r d}$, $6^{\text {th }}, 12^{\text {th }}$, and $24^{\text {th }}$ hours $(\mathrm{p}>0.05)$. The changes in HR and RR values within 24 hours are presented in Fig. 1 and 2, and the mean HR, RR, and $\mathrm{SpO}_{2}$ values are shown in Table 2. The time to a reduction of $\mathrm{HR}$ and RR of $20 \%$ of those receiving HFNC oxygen support was determined to be statistically significantly more rapid than in those receiving HFNC oxygen support $(p=0.001, p=0.001)$. Time to normalization of HR and RR was determined to be statistically significantly shorter in those receiving HFNC oxygen support $(p=0.002)$. Length of hospital stay $(p=$
$0.001)$ and duration of oxygen support $(p=0.001)$ were determined to be statistically significantly shorter in those receiving HFNC oxygen support (Table 3).

In correlation tests, a positive correlation was determined between attack scores and HR at 0 hours and length of hospital stay, although it was not statistically significant ( $p>0.05$ ). A statistically significant positive correlation was determined between time to normalization of HR and $\mathrm{RR}$ and length of hospital stay $(\mathrm{r}=0.92, \mathrm{p}=0.001)$. A statistically significant positive correlation was also determined between the duration of oxygen therapy and duration of hospital stay $(r=0.93, p=0.001)$.

Failure of vital signs to restore to age-adjusted normal ranges and of $\mathrm{SpO}_{2}$ to return back to normal within 24 hours were considered as treatment failure. It was observed that $7(87.5 \%)$ of 8 patients with treatment failure were in the NFM group $(\mathrm{p}=0.027)$, which was statistically significant. It was seen that two $(28.6 \%)$ of seven patients in the NFM group who had treatment failure developed a need for intensive care, which was statistically significant $(p=0.03)$. Only $2(2.7 \%)$ of all patients required follow-up in the intensive care unit (ICU), of which two were in the NFM group. The attack scores of these two patients were moderate. No statistical significance was determined between the need for intensive care and sex, attack scores, and treatment method $(\mathrm{p}>0.05)$. No complications occurred in either the HFNC or NFM groups. 
TA B L E 3. Alterations in vital signs, oxygen therapy and durations of hospital stay by groups.

\begin{tabular}{|c|c|c|c|}
\hline & $\begin{array}{l}\text { Oxygen via Mask with } \\
\text { Reservoir }(n=38)\end{array}$ & $\begin{array}{l}\text { Oxygen via High-Flow } \\
\text { Nasal Cannula }(n=37)\end{array}$ & $\mathbf{p}$ \\
\hline Time to a reduction in cardiac apex beat by $20 \%$ (hour) & $8.26 \pm 6.4$ & $2.81 \pm 1.8$ & 0.001 \\
\hline Time to a reduction in respiration rate by $20 \%$ (hour) & $12.65 \pm 8.18$ & $5.37 \pm 4.54$ & 0.001 \\
\hline $\begin{array}{l}\text { Time to normalization of cardiac apex beat } \\
\text { and respiration rate (hour) }\end{array}$ & $19.31 \pm 10.44$ & $10.13 \pm 7.82$ & 0.002 \\
\hline Duration of oxygen therapy (hour) & $25.21 \pm 10.53$ & $17.10 \pm 9.49$ & 0.001 \\
\hline Duration of hospital stay (hour) & $44.23 \pm 15.84$ & $31.05 \pm 11.92$ & 0.001 \\
\hline
\end{tabular}

\section{Discussion}

In this study, we compared the effectiveness of HFNC and NFM oxygen therapies in children with AB. Although there was a significant reduction in both $\mathrm{HR}$ and RR from the beginning of the treatment in those receiving HFNC oxygen therapy, there was a significant reduction in $\mathrm{RR}$ at the $3^{r d}$ hour and in HR at the $6^{\text {th }}$ hour of the treatment compared to NFM. The mean time to a reduction in RR of $20 \%$ was $5.37 \pm 4.54$ hours in those receiving HFNC group, and $2.81 \pm 1.80$ hours in the HFNC group. The time to normalization of HR and RR according to age and length of hospital stay were shorter and the need for intensive care support was less in the HFNC group.

HFNC support has been increasingly used for the treatment of $\mathrm{AB}$ and is thought to be effective and safe in infants and children. In order to measure disease severity, many centers use various respiration scores including tachypnea, acute respiratory distress, and lung aeration; however, there is no universally accepted respiratory scoring system among the currently available protocols [13]. As it is in all patients with respiratory distress and/or failure, early determination of success or failure of treatment in $\mathrm{AB}$ is important in regard to not increasing morbidity and mortality or developing a need for ICU stay. There is no standard in the follow-up of patients with $\mathrm{AB}$ and various invasive procedures (blood gas measurements, end-tidal carbon dioxide measurements or monitoring of clinical and vital signs) are used [14]. In our study, it was shown that follow-up can be done with non-invasive methods. Franklin et al. [15] used criteria such as respiratory support or need for the ICU, permanent tachycardia, tachypnea, and hypoxemia to determine treatment failure in their study of 1472 patients with bronchiolitis. By contrast, Kallappa et al. [16] preferred to use blood gas parameters in addition to HR and RR for the follow-up of patients. In our study, the evaluation of effectiveness and response to treatment of bronchiolitis in patients whose diagnosis was based upon histories and physical examinations was performed using $\mathrm{HR}$ and $\mathrm{RR}$ in addition to clinical findings (e.g. retraction, increased respiratory effort, cyanosis, poor perfusion, apnea, neurologic disorders). None of our patients receiving HFNC oxygen were given NIV or IMV support, hospitalized in the ICU, and all were discharged with cure. This, therefore, suggests that these patients could be followed up using clinical and vital signs without the need for invasive monitoring such as blood gas measurement. These parameters would be sufficient for determining the efficacy of HFNC or continuing to the next treatment step.

In the study conducted by Bressan et al. [17], however, it was reported that $\mathrm{SpO}_{2}$ values exhibited a statistically significant increase after the treatment of patients receiving standard oxygen therapy was changed to HFNC, which increased $\mathrm{SpO}_{2}$ levels. This, in turn, was associated with the reduction of end-tidal carbon dioxide and RR. Physiologic data based on oxyhemoglobin dissociation curves demonstrate that minimal increases in arterial partial oxygen pressure are associated with marked improvement in pulse-oximetry when $\mathrm{SpO}_{2}$ is less than $90 \%$. Also, when $\mathrm{SpO}_{2}$ is higher than $90 \%$, greater increases in arterial partial pressure of oxygen are required to influence pulse-oximetry [3]. In our study, $\mathrm{SpO}_{2}$ values increased within first hour of HFNC oxygen therapy, but $\mathrm{SpO}_{2}$ was also determined to be increased in those receiving NFM oxygen therapy. This indicates that the oxygen support provided led to a small increase in arterial partial oxygen pressure, causing a relative improvement in pulse-oximetry and that, independently of clinical and vital signs, $\mathrm{SpO}_{2}$ monitoring alone was not sufficient for follow up of these patients' status.

In the literature, the effectiveness of HFNC oxygen therapy has been compared between different patient groups and with different methods such as continuous positive airway pressure, and nasal, hood, simple face mask, and non-rebreathing face mask oxygen therapy. When previous studies were reviewed, it was observed that HFNC oxygen therapy has been compared with nasal oxygen support among low-flow oxygen administration methods [18-20]. In the study conducted by McKiernan et al. [5], a significant reduction in respiration rate was recorded within the first hour after initiation of treatment in patients with bronchiolitis treated with HFNC, which was not observed in those who received other oxygen and respiratory support methods. Kelly et al. [21] analyzed 498 infants and children with respiratory distress in the emergency department and found that almost half were admitted due to bronchiolitis. The authors determined that the patients responded to HFNC within three hours of treatment onset. In the study by Mayfield et al. [14] in which HFNC and lowflow oxygen therapies were compared in patients with $\mathrm{AB}$ in the emergency department, it was determined that no change occurred in HR and RR in patients who did not respond to HFNC and developed a need for ICU, and there 
was a reduction in HR and RR in those who responded. Consistent with the literature, in our study there was a reduction in HR and RR from the first hour of treatment, and it was determined that there was a statistically significant reduction in HR at the sixth hour of treatment and in RR at the third hour of treatment, compared with NFM.

Franklin et al. [15] compared HFNC and standard oxygen therapies in patients with bronchiolitis, and it was reported that rate of adverse effects was low in both groups; pneumothorax that did not require drainage developed in both groups and no severe life-threatening adverse effects including emergency intubation or cardiac arrest were observed. Congruent to the literature, none of our patients developed complications. This indicates that a flow rate up to $25 \mathrm{~L} / \mathrm{min}$ could be safely used for patients aged under two years.

In previous studies, it has been revealed that success rate of HFNC is over $90 \%$ in patients with bronchiolitis, and the rate of intubation decreases among these patients $[5,21$, 22]. McKiernan et al. [5] reported that HFNC decreased $\mathrm{RR}$ and respiratory effort in infants with bronchiolitis and thus prevented the need for mechanical ventilation. Also, in our study, in line with the literature, the two patients requiring intensive care were in the NFM group. In the study by Mayfield et al. [14] in which patients given HFNC and standard oxygen were compared, it was observed that there was no difference between the groups in regard to length of hospital stay. In contrast, Manley et al. [23] reported that both the length of hospital stay and duration of oxygen therapy of patients in the HFNC group were shorter among the patients they treated with HFNC and CPAP after extubation. Similar to the study of Manley et al., both the length of hospital stay and duration of oxygen therapy of those receiving HFNC treatment were shorter in our study.

\section{Conclusion}

HFNC is a non-invasive, simple, effective, easy-to-use, and safe respiratory support method for patients diagnosed with bronchiolitis. The most important issue is early prediction of HFNC failure and not losing time in progressing to another aeration support method or for providing intensive care support. HFNC significantly shortens duration of hospital stay and duration of oxygen therapy compared to standard oxygen, and it is thought that the effectiveness of treatment or response to treatment could be evaluated using $\mathrm{HR}$ and RR monitoring. A flow rate up to $25 \mathrm{~L} / \mathrm{min}$ could be used for patients aged under two years.

\section{AUTHOR CONTRIBUTIONS}

Concept: E.T, A.Y, S.P, F.A; Design: E.T.,A.Y F.A, S.P.; Data Collection or Processing: E.T, A.Y, S.P.; Analysis or Interpretation: E.T, A.Y, F.A, S.P.; Literature Search: E.T; Writing: E.T.

\section{ACKNOWLEDGEMENTS}

I would like to express my gratitude to all nurses and pediatrics residents who helped me during patient followup in Meram Faculty of Medicine, Department of Pediatric Emergency. Thanks to all the peer reviewers and editors for their opinions and suggestions.

\section{CONFLICT OF INTEREST}

The authors declare no conflict of interest.

\section{ETHICAL APPROVAL}

The approval of the local Ethics Committee was obtained

\section{FUNDING INFORMATION}

Financial support was not received for this study, the costs were covered by the authors

\section{REFERENCES}

[1] Healthcare Cost and Utilization Project (HCUP). The HCUP Kids' Inpatient Database (KID). Rockville, MD: Agency for Healthcare Research and Quality; 2005.

[2] Smyth RL, Openshaw PJ. Bronchiolitis. Lancet. 2006;368:312-322.

[3] Ralston SL, Lieberthal AS, Meissner HC, Alverson BK, Baley JE, Gadomski AM, et al. 3rd, Hernandez-Cancio S; American Academy of Pediatrics. Clinical practice guideline: the diagnosis, management, and prevention of bronchiolitis. Pediatrics. 2014;134:e1474-502.

[4] Hartling L, Fernandes RM, Bialy L, Milne A, Johnson D, Plint A, et al. Steroids and bronchodilators for acute bronchiolitis in the first two years of life: systematic review and meta-analysis. BMJ. 2011;342:d1714.

[5] McKiernan C, Chua LC, Visintainer PF, Allen H. High-flow nasal cannulae therapy in infants with bronchiolitis. J Pediatr. 2010;156:634-638.

[6] Kepreotes E, Whitehead B, Attia J, Oldmeadow C, Collison A, Searles A, et al. High-flow warm humidified oxygen versus standard low-flow nasal cannula oxygen for moderate bronchiolitis (HFWHO RCT): an open, phase 4, randomised controlled trial. Lancet. 2017;389:930-939.

[7] Milési C, Essouri S, Pouyau R, Liet JM, Afanetti M, Portefaix A, et al; Groupe Francophone de Réanimation et d'Urgences Pédiatriques (GFRUP). High flow nasal cannula (HFNC) versus nasal continuous positive airway pressure (nCPAP) for the initial respiratory management of acute viral bronchiolitis in young infants: a multicenter randomized controlled trial (TRAMONTANE study). Intensive Care Med. 2017;43:209-216.

${ }^{[8]}$ Frat JP, Thille AW, Mercat A, Girault C, Ragot S, Perbet S, et al; FLORALI Study Group; REVA Network. High-flow oxygen through nasal cannula in acute hypoxemic respiratory failure. N Engl J Med. 2015;372:2185-2196.

[9] Lee JH, Rehder KJ, Williford L, Cheifetz IM, Turner DA. Use of high-flow nasal cannula in critically ill infants, children, and adults: a critical review of the literature. Intensive Care Med. 2013;39:247257.

[10] Dysart K, Miller TL, Wolfson MR, Shaffer TH. Research in high-flow therapy: mechanisms of action. Respir Med. 2009;103:1400-1405.

[11] Hutchings FA, Hilliard TN, Davis PJ. Heated humidified high-flow nasal cannula therapy in children. Arch Dis Child. 2015;100:571-575.

[12] Wang EE, Milner RA, Navas L, Maj H. Observer agreement for 
respiratory signs and oximetry in infants hospitalized with lower respiratory infections. Am Rev Respir Dis. 1992;145:106-109.

[13] Kline J, Kalburgi S, Halley T. High-flow nasal cannula therapy for bronchiolitis across the emergency department and acute care floor. Clin Pediatr Emerg Med. 2018;19:40-45.

[14] Mayfield S, Bogossian F, O'Malley L, Schibler A. High-flow nasal cannula oxygen therapy for infants with bronchiolitis: pilot study. J Paediatr Child Health. 2014;50:373-378.

[15] Franklin D, Babl FE, Schlapbach LJ, Oakley E, Craig S, Neutze J, et al. A randomized trial of high-flow oxygen therapy in infants with bronchiolitis. N Engl J Med. 2018;378:1121-1131.

[16] Kallappa C, Hufton M, Millen G, Ninan TK. Use of high-flow nasal cannula oxygen (HFNCO) in infants with bronchiolitis on a paediatric ward: a 3-year experience. Arch Dis Child. 2014;99:790-791.

[17] Bressan S, Balzani M, Krauss B, Pettenazzo A, Zanconato S, Baraldi E. High-flow nasal cannula oxygen for bronchiolitis in a pediatric ward: a pilot study. Eur J Pediatr. 2013;172:1649-1656.

[18] Mikalsen IB, Davis P, Øymar K. High-flow nasal cannula in children: a literature review. Scand J Trauma Resusc Emerg Med. 2016;24:93.

[19] Franklin D, Schibler A. Nasal high-flow therapy in infants and children. Pediatr Respirol Crit Care Med. 2018;2:2-6.
[20] Beggs S, Wong ZH, Kaul S, Ogden KJ, Walters JA. High-flow nasal cannula therapy for infants with bronchiolitis. Cochrane Database Syst Rev. 2014;20:CD009609.

[21] Kelly GS, Simon HK, Sturm JJ. High-flow nasal cannula use in children with respiratory distress in the emergency department: predicting the need for subsequent intubation. Pediatr Emerg Care. 2013;29:888-892.

[22] Schibler A, Pham TM, Dunster KR, Foster K, Barlow A, Gibbons K, et al. Reduced intubation rates for infants after introduction of highflow nasal prong oxygen delivery. Intensive Care Med. 2011;37:847852.

[23] Manley BJ, Owen LS, Doyle LW, Andersen CC, Cartwright DW, Pritchard MA, et al. High-flow nasal cannulae in very preterm infants after extubation. N Engl J Med. 2013;369:1425-1433.

How to cite this article: Esra Türe, Abdullah Yazar, Fatih Akın, Sevgi Pekcan. High-flow Nasal Cannula is Superior to Standard Face-Mask Oxygen Therapy in Viral Bronchiolitis. Signa Vitae.2020;16(1):47-53. doi:10.22514/sv.2020.16.0007. 